\title{
Role of primary care in the follow-up of patients with obstructive sleep apnoea undergoing CPAP treatment: a randomised controlled trial
}

\author{
M Sánchez-de-la-Torre, ${ }^{1,2} \mathrm{~N}$ Nadal, ${ }^{1,3}$ A Cortijo, ${ }^{1}$ JF Masa, ${ }^{2,4}$ J Duran-Cantolla, ${ }^{2,5}$ \\ J Valls, ${ }^{6}$ S Serra, ${ }^{1}$ A Sánchez-de-la-Torre, ${ }^{1,2}$ M Gracia, ${ }^{3}$ F Ferrer, ${ }^{3}$ I Lorente, ${ }^{3}$ \\ M C Urgeles, ${ }^{3}$ T Alonso, ${ }^{3}$ A Fuentes, ${ }^{3} \mathrm{~F}$ Armengol, ${ }^{3} \mathrm{M}$ Lumbierres, ${ }^{1}$ \\ F J Vázquez-Polo, ${ }^{7}$ F Barbé, ${ }^{1,2}$ for the Respiratory Medicine Research Group
}

- Additional material is published online only. To view please visit the journal online (http://dx.doi.org/10.1136/ thoraxjnl-2014-206287).

${ }^{1}$ Respiratory Department, Arnau de Vilanova-Santa María University Hospital, IRB Lleida, Lleida, Catalonia, Spain ${ }^{2}$ Centro de Investigación Biomédica en Red de Enfermedades Respiratorias (CIBERES), Madrid, Spain ${ }^{3}$ Primary Care Unit of Lleida, Catalonia, Spain

${ }^{4}$ Respiratory Department, San Pedro de Alcantara Hospital, Cáceres, Spain

${ }^{5}$ Araba University Hospital, UPV, BioAraba Institute, Vitoria, Spain

${ }^{6}$ Department of Statistics, IRB Lleida, Catalonia, Spain

${ }^{7}$ Las Palmas de Gran Canaria University, Las Palmas de Gran Canaria, Spain

\section{Correspondence to} Dr Ferran Barbé, Respiratory Department, Hospital Univ Arnau de Vilanova, Rovira Roure, 80, Lleida 25198, Spain;

febarbe.lleida.ics@gencat.cat

Received 5 September 2014 Revised 29 December 2014 Accepted 28 January 2015

\section{CrossMark}

\footnotetext{
To cite: Sánchez-de-laTorre M, Nadal N, Cortijo A, et al. Thorax 2015;70: 346-352.
}

\section{ABSTRACT}

Objective To evaluate whether follow-up of patients with obstructive sleep apnoea (OSA) undergoing CPAP treatment could be performed in primary care (PC) settings.

Design Non-inferiority, randomised, prospective controlled study.

Settings Sleep unit (SU) at the University Hospital and in 8 PC units in Lleida, Spain.

Participants Patients with OSA were randomised to be followed up at the SU or PC units over a 6-month period.

Main outcomes measured The primary outcome was CPAP compliance at 6 months. The secondary outcomes were Epworth Sleep Scale (ESS) score, EuroQoL, patient satisfaction, body mass index (BMI), blood pressure and cost-effectiveness.

Results We included 101 patients in PC ((mean \pm SD) apnoea-hypopnoea index (AHI) 50.8 22.9/h, age 56.2 \pm 11 years, $74 \%$ male) and 109 in the SU (AHI 51.4 $\pm 24.4 / \mathrm{h}$, age $55.8 \pm 11$ years, $77 \%$ male)). The (PAP compliance was (mean $(95 \% \mathrm{Cl}) 4.94$ (4.47 to 5.5$)$ vs 5.23 (4.79 to 5.66) $h, p=0.18$ ) in PC and SU groups, respectively. In the SU group, there were greater improvements in ESS scores (mean change 1.79, 95\% $\mathrm{Cl}+0.05$ to $+3.53, \mathrm{p}=0.04)$ and patient satisfaction $(-1.49,95 \% \mathrm{Cl}-2.22$ to -0.76$)$; there was a significant mean difference in BMI between the groups $(0.57,95 \% \mathrm{Cl}+0.01$ to $+1.13, \mathrm{p}=0.04)$. In the $\mathrm{PC}$ setting, there was a cost saving of $60 \%$, with similar effectiveness, as well as a decrease in systolic blood pressure $(-5.32 ; 95 \% \mathrm{Cl}-10.91$ to $+0.28, \mathrm{p}=0.06)$. Conclusions For patients with OSA, treatment provided in a PC setting did not result in worse CPAP compliance compared with a specialist model and was shown to be a cost-effective alternative.

Trial registration number Clinical Trials NCT01918449.

\section{INTRODUCTION}

Obstructive sleep apnoea syndrome (OSA) is a highly prevalent disease ${ }^{1-3}$ that has been shown to be associated with reduced quality of life $^{4}$ and the onset or worsening of hypertension, ${ }^{5}{ }^{6}$ cardiovascular diseases, ${ }^{7}$ stroke, ${ }^{8}$ increased traffic and workplace accidents ${ }^{9}{ }^{10}$ and mortality. ${ }^{11}$ OSA

\section{Key messages}

What is the key question?

- Is CPAP treatment compliance followed up by primary care physicians as effective as conventional CPAP management in a sleep unit?

\section{What is the bottom line?}

- Because the number of patients undergoing CPAP treatment is increasing and overloading the follow-up resources of health systems, alternatives to traditional methods must be considered to guarantee effective, efficient and integrated patient care and management.

\section{Why read on?}

- This randomised controlled trial shows that a new model involving primary care settings is a realistic and cost-effective alternative to conventional follow-up in a sleep unit.

management is challenging for health systems; generally, it is based in a hospital sleep unit (SU). This approach is expensive and not available at all hospitals. In addition, waiting lists for sleep physician consultation and laboratory-based polysomnography are often long. Thus, there has been increasing interest in the use of screening questionnaires, home sleep monitoring and ambulatory management for OSA. Several randomised controlled studies have shown that this approach produces comparable treatment compliance and clinical improvement compared with standard laboratorybased sleep studies and follow-ups. ${ }^{12-16}$ In this new scenario, there is a great interest in involving other healthcare professionals in the treatment. Indeed, primary care (PC) physicians must be involved in managing any common disease. ${ }^{17}$

Treating OSA with CPAP improves symptoms and quality of life, decreases traffic accidents and may positively affect cardiovascular morbidity. ${ }^{6} 1819$ The effectiveness of this treatment is directly related to compliance. ${ }^{20}{ }^{21}$ Strict follow-up is required for improvement, particularly in the first 
few months. ${ }^{20}$ The number of patients undergoing CPAP treatment has increased consistently in recent years, ${ }^{22}$ which has overloaded follow-up resources. To guarantee effective, efficient and integral patient care and management, alternatives to traditional methods must be considered. ${ }^{22} 23$ The aim of this study was to determine whether treatment follow-up by PC physicians is as effective (that is, with similar compliance and clinical response) as conventional management of patients with OSA who begin CPAP treatment in an SU. Thus, we investigated whether this new model was a realistic alternative to conventional SU follow-up.

\section{METHODS}

\section{Study design}

We performed a randomised, controlled, prospective parallelgroup study to examine the efficacy of $\mathrm{PC}$ versus conventional SU follow-up of patients with OSA beginning CPAP treatment. The study was registered with the USA National Institutes of Health (ClinicalTrials.gov, NCT01918449). Each participant was interviewed and informed in detail about the purpose of this study. The ethics committee at our institution approved the study (CEIC-884). All participants provided written informed consent.

\section{Settings and participants}

This study was conducted in the SU of one teaching hospital and eight PC units in Lleida (Catalonia, Spain). The patients were recruited from the SU at our hospital beginning in January 2013. Follow-up ended in December 2013. We included men and women aged $\geq 18$ years who had just been diagnosed with OSA and required CPAP treatment. The treatment was based on national guidelines. ${ }^{24}$ Briefly, the indications for CPAP treatment are 30 or more apnoea and hypopnoea episodes per hour (ie, apnoea-hypopnoea index (AHI)) in an overnight sleep study, daytime hypersomnolence (defined as an Epworth Sleep Scale (ESS) score $\geq 10$ ) and/or high cardiovascular risk. The exclusion criteria for this study were relevant impaired lung function (overlap syndrome, obesity hypoventilation syndrome and restrictive disorders), the presence of comorbidities (severe psychiatric disorders, periodic leg movements or other dyssomnias or parasomnias) and previous CPAP treatment.

OSA was diagnosed using a conventional polysomnographic or respiratory sleep study. The respiratory study included (at a minimum) continuous recording from a nasal cannulae, thoracic-abdominal motion, oxygen saturation and body position. The results of all sleep studies were analysed by trained personnel from the SU at our hospital using standard criteria. Apnoea was defined as the absence of airflow for $\geq 10 \mathrm{~s}$ and hypopnoea was defined as an airflow reduction $(>50 \%)$ lasting $\geq 10$ s with a $>4 \%$ decrease in oxygen saturation. ${ }^{25}$ Obstructive apnoea was defined as the absence of airflow in the presence of chest or abdominal wall motion. The AHI was calculated based on the average number of apnoea plus hypopnoea episodes per hour of sleep or recording time.

CPAP was titrated using an auto-CPAP device (Autoset-T, ResMed, Sydney, Australia) according to a previous validation by the Spanish Sleep and Breathing Group. ${ }^{26}$ The recording was repeated for two additional nights if the original recording was unacceptable. Optimal pressure was determined visually from the raw data from the auto-CPAP device by analysing the pressure curve, which included the periods with a leak lower than $0.4 \mathrm{~L} / \mathrm{s}$ (90th centile). After the optimal pressure was achieved, at-home treatment was initiated with a fixed CPAP level.
The diagnosis of OSA and the CPAP titration were performed at the SU in the same manner for all patients in the study.

\section{Randomisation and interventions}

The patients who were diagnosed with OSA in the SU and required CPAP treatment were randomly assigned in a 1:1 ratio to either PC management or SU management. Randomisation was performed using a computer-generated list of random numbers. All patients received sleep hygiene and hygienicdietary measures. The patients were followed up for 1,3 and 6 months by specialised nursing at the SU or by a general practitioner/nurse in the PC setting. At each visit, the patients received education and support for setting up and using the CPAP device, advice on managing CPAP-related adverse effects, encouragement for CPAP compliance and education about lifestyle changes. In addition, the patients were asked to complete the research questionnaires.

\section{PC training}

One PC physician and one nurse from each of the eight PC units in the study participated in an education programme $(6 \mathrm{~h})$ that included the theoretical and practical aspects managing patients with sleep apnoea. None of the participating members of the PC centres had received specific training in managing patients with OSA before completing the education programme. The education programme was delivered by the sleep physician and nurse specialist from the SU who managed the CPAP treatment of the patients in this study who were randomised to the SU group.

\section{PC management}

The patients' treatment was managed by PC physicians and a community-based nurse who participated in an education programme $(6 \mathrm{~h})$ that included the theoretical and practical aspects of managing patients with sleep apnoea. The patients were followed up in person by a PC physician or a community-based nurse to review their progress and provide support for the CPAP setup and education, advice about managing CPAP-related adverse effects, encouragement to comply with CPAP recommendations and adhere to its use and education about lifestyle changes. Additionally, the patients were asked to complete relevant research questionnaires. The patients were followed up at 1, 3 and 6 months. Additionally, if necessary, the patients could have telephone consultations with the PC physician or nurse who performed the follow-up visits. The same day of the telephone consultation the patients were attended by telephone. CPAP adherence was objectively recorded by the device.

\section{Specialist SU management}

Conventional SU patient management was performed by the SU specialist nurse (or by the consulting specialist nurse to a specialist doctor, if necessary). The patients met the PC physician or community-based nurse in person to review their progress and receive education about, and support for, the CPAP setup, advice about managing CPAP-related adverse effects, encouragement to comply with the CPAP recommendations and to adhere to its use and education about lifestyle changes. Additionally, the patients were asked to complete relevant research questionnaires. The patients were followed up at 1,3 and 6 months. Additionally, if necessary, the patients could have telephone consultations with the specialist nurse who performed the follow-up visits. The same day of the telephone consultation the patients were attended by telephone. CPAP adherence was objectively recorded by the device. 


\section{Outcomes and follow-up}

Primary outcome

The primary outcome was CPAP compliance 6 months after treatment was started. Compliance was objectively measured using the number of hours of CPAP use per day according to the CPAP device's internal clock.

\section{Secondary outcomes}

From baseline to 6 months, we evaluated the change in ESS score ${ }^{27}$ the EuroQoL five-dimensions questionnaire (EQ-5D, administered to measure the patients' health states), patient satisfaction (measured using a visual analogue scale ranging from 0 to 10$)$, body mass index (BMI) and office blood pressure. ${ }^{28}$ Additionally, a cost-effectiveness analysis was performed. The costs were based on Catalan Institute of Health tables (CVE-DOGC-A-13051031-2013). The within-trial cost calculation methodology is described in the online supplementary material.

\section{Statistical analysis}

The Mann-Whitney U test and Fisher's exact test were performed to assess the differences in baseline characteristics between the groups. Fisher's test was used to evaluate whether the between-group abandonment rates differed. A multiple imputation procedure using a Bayesian approach was used to replace the missing data for the primary and secondary outcome variables and an intention-to-treat analysis was performed that resulted in 10 complete datasets. The $\mathrm{R}$ package 'mi' ${ }^{29}$ was used for these calculations. Linear and logistic regression models were used to assess the differences between the SU and PC patients for each complete dataset. These models used the formulas proposed by Rubin. ${ }^{30}$ The difference in the mean CPAP compliance was evaluated using a linear model to determine the non-inferiority of the PC group with respect to the SU group. For these models, significance was assessed using a one-sided $\mathrm{p}$ value and 95\% (CIs) intervals. For the secondary outcome measures, two-sided tests and CIs were used, and specific evaluations of the mean change after 6 months were considered for the EQ-5D, BMI, ESS, systolic blood pressure (SBP) and diastolic blood pressure (DBP). The models were also adjusted using the baseline characteristics with statistically significant between-group differences; in addition, for the SBP and DBP, the use of antihypertensive drugs was also adjusted in the models.

For the primary and secondary outcomes, a sensitivity analysis was conducted to compare the results obtained when analysing the data only of those patients who completed the study.

\section{Sample size}

The sample size was determined to permit assessments of the non-inferiority of CPAP compliance in the PC settings compared with the SU setting, with a non-inferiority margin of $-1 \mathrm{~h}$ per night (based on expert agreement). Power computations indicated that the inclusion of 210 patients was sufficient to achieve a $90 \%$ statistical power for detecting a significant difference (with a type 1 error of 5\%), assuming a SD of 2.5 (moderately above the values previously reported in similar studies).

\section{RESULTS}

Figure 1 shows a flow diagram outlining the recruitment and randomisation pathway. We studied 235 patients with OSA who were diagnosed in the SU and required CPAP treatment. Among those patients, 210 agreed to participate and were eligible. The patients were randomised as follows: 101 patients were randomised to receive PC management and 109 were randomised to receive SU management. Both groups were comparable and consisted of predominantly middle-aged obese men with severe OSA (table 1). As a random effect, BMI was significantly higher in the SU group (with a difference of $2.1 \mathrm{~kg} / \mathrm{m}^{2}$ ).

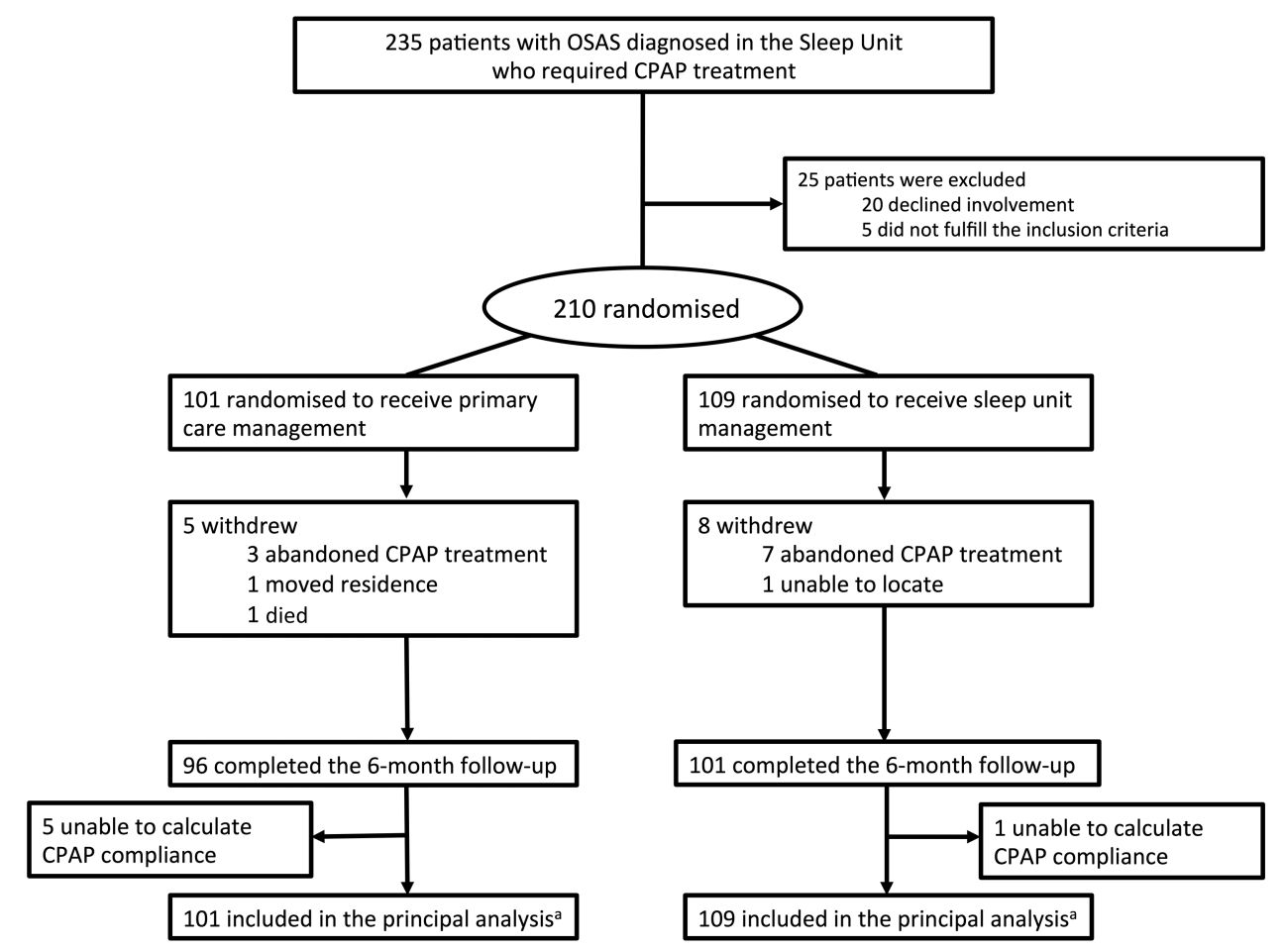

Figure 1 Study flow chart. ${ }^{\text {T}}$ The primary analysis was conducted in an intention-to-treat manner and missing values were replaced using multiple imputation. OSAS, obstructive sleep apnoea syndrome. 
Table 1 Baseline characteristics of the patients

\begin{tabular}{lccl}
\hline Characteristics & $\begin{array}{l}\text { Primary care } \\
(\mathbf{n}=101)\end{array}$ & $\begin{array}{l}\text { Sleep unit } \\
(\mathbf{n}=109)\end{array}$ & p Value \\
\hline Men, $\mathrm{n}(\%)$ & $75(74)$ & $84(77)$ & 0.6 \\
Age (years) & $56.2(11)$ & $55.8(11)$ & 0.8 \\
BMI (kg/m ${ }^{2}$ ) & $32.5(6)$ & $34.6(7.3)$ & 0.03 \\
Neck circumference (cm) & $42(4)$ & $43(4)$ & 0.09 \\
Waist circumference (cm) & $108.8(13.3)$ & $111.3(12.7)$ & 0.2 \\
Charlson Comorbidity Index & $1.3(1.4)$ & $1.4(1)$ & 0.66 \\
SBP (mm Hg) & $135(19.7)$ & $134.6(15.8)$ & 0.9 \\
DBP (mm Hg) & $81.3(11.8)$ & $84.3(11.1)$ & 0.06 \\
ESS score & $10.4(6)$ & $10.6(5.2)$ & 0.8 \\
AHI (per hour) & $50.8(22.9)$ & $51.4(24.4)$ & 0.8 \\
SaO ${ }_{2}$ drop $\geq 4 \%$ (events/h) & $31.6(26.7)$ & $33.8(28.7)$ & 0.7 \\
\hline Results are shown as mean (SD) unless stated otherwise. & \\
The statistically significant $p$ values ( $p$ values <0.05) are denoted in bold. & \\
AHI, apnoea-hypopnea index; BMI, body mass index; DBP, diastolic blood pressure; & \\
ESS, Epworth Sleep Scale; SBP, systolic blood pressure. & & \\
&
\end{tabular}

\section{Outcomes}

Primary outcome

The percentages of patients who abandoned the study during the follow-up were $2.9 \%$ and $6.4 \%$ in the PC and SU groups, respectively $(p=0.22)$. At 6 months, the mean CPAP compliance for the entire study population was $5 \mathrm{~h}$ per night $(95 \% \mathrm{CI} 4.6$ to 5.6). The mean CPAP compliance in the PC group was $4.94 \mathrm{~h}$ per night (95\% CI 4.47 to 5.5$)$ and the mean CPAP compliance in the SU group was $5.23 \mathrm{~h}$ per night (95\% CI 4.79 to 5.66 ), with a difference of -0.29 (the lower bound of a one-sided $95 \%$ $\mathrm{CI}-0.85)$ hours per night $(\mathrm{p}=0.18$; table 2$)$. Sensitivity analyses using only the data from the patients who completed the study (91 patients in the PC group and 100 in the SU group) produced similar results (ie, the difference in the mean CPAP compliance was -0.42 ; the lower bound of a one-sided 95\% CI -0.94 ; $\mathrm{p}=0.18$ ). These results support the non-inferiority of PC management because the lower bounds of the one-sided 95\% CI for all analyses were greater than the prespecified non-inferiority margin of $-1 \mathrm{~h}$ per night. After the models were adjusted for the BMI at baseline, the results did not change.

\section{Secondary outcomes}

The secondary outcome measures are shown in table 2. At 6 months, there was a decrease in the ESS score in both the PC $(\mathrm{p}<0.001)$ and SU groups $(\mathrm{p}<0.001)$. The decrease in the ESS score was greater in the SU group $(\mathrm{p}=0.04)$ and patient satisfaction was significantly higher in the SU group $(p<0.001)$.

Table 2. Analysis of primary outcome and secondary outcomes measured at 6 months.

\begin{tabular}{|c|c|c|c|c|c|c|}
\hline & $\begin{array}{l}\text { Primary care }(n=101) \\
\text { Mean }(95 \% \mathrm{Cl})\end{array}$ & $\begin{array}{l}\text { Sleep unit }(n=109) \\
\text { Mean }(95 \% \mathrm{Cl})\end{array}$ & $\begin{array}{l}\text { Difference in } \\
\text { mean change } \\
\text { Mean }(95 \% \mathrm{Cl})\end{array}$ & $P$ value & $\begin{array}{l}\text { BMI-adjusted } \\
\text { p value }\end{array}$ & $\begin{array}{l}\text { Antihypertensive } \\
\text { drugs-adjusted } \\
\mathrm{P} \text { value }\end{array}$ \\
\hline \multicolumn{7}{|l|}{ Primary outcome } \\
\hline $\begin{array}{l}\text { CPAP compliance } \\
\text { (hours/night) }\end{array}$ & $4.94(4.47$ to 5.50$)$ & 5.23 (4.79 to 5.66$)$ & $-0.29(-0.85)^{*}$ & $0.18^{\dagger}$ & $0.15^{\dagger}$ & \\
\hline \multicolumn{7}{|l|}{ Secondary outcomes } \\
\hline \multicolumn{7}{|c|}{ Epworth Sleep Scale Score } \\
\hline Baseline & 10.50 (9.37 to 11.62$)$ & 10.55 (9.46 to 11.64$)$ & & & & \\
\hline 6-months & 5.92 (5.04 to 6.80$)$ & 4.18 (3.26 to 5.10$)$ & & & & \\
\hline Change & $-4.58(-5.79 \text { to }-3.36)^{\S}$ & $-6.37(-7.55 \text { to }-5.19)^{\S}$ & $1.79(0.05$ to 3.53$)$ & 0.04 & 0.049 & \\
\hline $\begin{array}{l}\text { Patient satisfaction at } \\
6 \text { months }^{\ddagger}\end{array}$ & 7.54 (7.01 to 8.08$)$ & 9.03 (8.50 to 9.56 ) & $-1.49(-2.22$ to -0.76$)$ & $<0.001$ & $<0.001$ & \\
\hline \multicolumn{7}{|l|}{ EQ-5D } \\
\hline Baseline & 0.77 (0.73 to 0.81$)$ & 0.79 (0.75 to 0.83$)$ & & & & \\
\hline 6-months & 0.81 (0.77 to 0.86$)$ & $0.86(0.82$ to 0.90$)$ & & & & \\
\hline Change & $0.04(-0.01$ to 0.08$)$ & $0.07(0.03 \text { to } 0.11)^{\S}$ & $-0.03(-0.09$ to 0.02$)$ & 0.25 & 0.33 & \\
\hline \multicolumn{7}{|c|}{ Body mass index $\left(\mathrm{kg} / \mathrm{m}^{2}\right)$} \\
\hline Baseline & 32.53 (31.19 to 33.86$)$ & 34.57 (33.28 to 35.85$)$ & & & & \\
\hline 6 -months & 33.06 (31.70 to 34.42 ) & 34.53 (33.23 to 35.84 ) & & & & \\
\hline Change & $0.54(0.12 \text { to } 0.95)^{\S}$ & $-0.03(-0.42$ to 0.36$)$ & 0.57 (0.01 to 1.13 ) & 0.04 & - & \\
\hline \multicolumn{7}{|c|}{ Systolic blood pressure $(\mathrm{mm} \mathrm{Hg})$} \\
\hline Baseline & 135.06 (131.14 to 138.99$)$ & 134.57 (131.06 to 138.08$)$ & & & & \\
\hline 6-months & 131.29 (127.40 to 135.17$)$ & 136.11 (132.66 to 139.56$)$ & & & & \\
\hline Change & $-3.78(-8.62$ to 1.07$)$ & $1.54(-1.93$ to 5.01$)$ & $-5.32(-10.91$ to 0.28$)$ & 0.06 & 0.07 & 0.14 \\
\hline \multicolumn{7}{|c|}{ Diastolic blood pressure $(\mathrm{mm} \mathrm{Hg})$} \\
\hline Baseline & 81.26 (78.75 to 83.77$)$ & 84.36 (82.11 to 86.61$)$ & & & & \\
\hline 6-months & 79.54 (76.96 to 82.12 ) & 85.00 (82.49 to 87.51$)$ & & & & \\
\hline Change & $-1.72(-4.91$ to 1.46$)$ & $0.64(-2.08$ to 3.36$)$ & $-2.36(-6.13$ to 1.41$)$ & 0.21 & 0.22 & 0.38 \\
\hline
\end{tabular}

Change computed as the difference of the 6 -months values with respect to the baseline values.

Difference in mean change computed as the difference of Primary Care with respect to Sleep Unit values.

BMl; Body Mass Index, EQ; EuroQol.

${ }^{*}$ Mean (one-sided $95 \% \mathrm{Cl}$, lower bound).

tOne-sided p-values.

$\ddagger$ Patient satisfaction visual scale (range from 0 to 10 ).

$\S \mathrm{P}<0.001$ for paired comparison of outcome measures examining change from baseline to 6 months.

The statistically significant $p$ values ( $p$ values lower than 0.05 ) are bolded. 


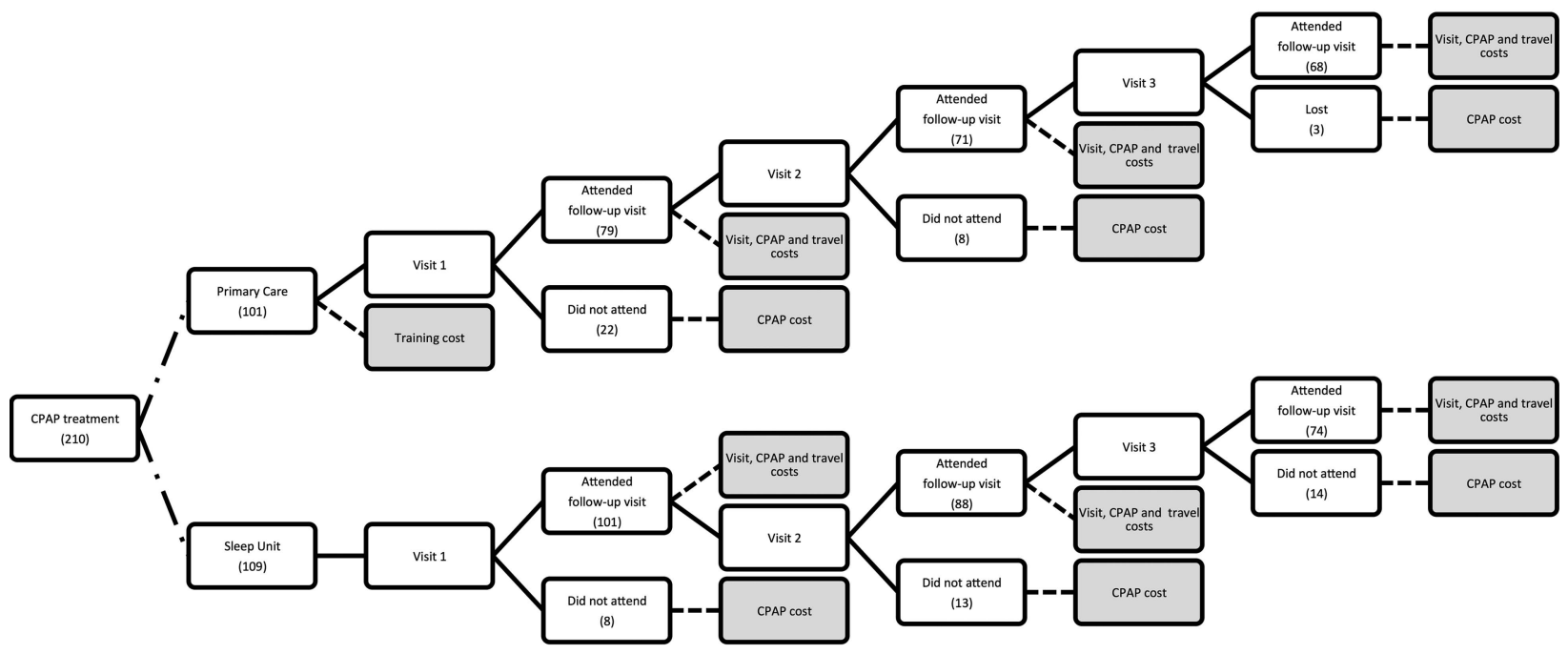

Figure 2 A flow chart of the patients and cost imputation. After CPAP was prescribed, the patients were randomised to either a primary care (PC) or sleep unit setting for treatment and follow-up (6 months). In both groups, the decision nodes were determined by the patients who complied with the three planned visits. The cost imputation nodes included the expenditure items at each visit. For the patients who did not comply with the visits (lost to follow-up), only the CPAP cost at that moment was included. Any additional burden due to the training course was charged only for the PC arm.

At 6 months, the EQ-5D results improved in both the SU group $(p<0.001)$ and the PC group $(p=0.08)$. The difference in the mean improvement between the groups was not significant $(\mathrm{p}=0.25)$.

The BMI did not change in the SU group; however, a small but statistically significant increase of $0.57 \mathrm{~kg} / \mathrm{m}^{2}$ was seen in the PC group ( $\mathrm{p}=0.04)$.

After 6 months, no differences in DBP were evident in either the PC or SU groups. Systolic pressure tended to decrease in the PC group ( $p=0.12)$. Additionally, a between-group difference in the mean SBP change $(p=0.06)$ was also seen; however, after adjusting for changes in antihypertensive treatment, this difference was not statistically significant $(p=0.14)$.

\section{Within-trial costs}

A comparison of within-trial management costs (figure 2) was performed. Table 3 shows the costs for the PC and SU settings as the calculated cost groups for the included patients. A cost evaluation showed a total average cost per randomised patient of $€ 144$ in the PC group and $€ 356$ in the SU group. The cost differences were primarily related to the clinical monitoring performed by specialist nurses in the SU. The average cost per randomised patient was higher for the SU group than for the PC group. Additionally, variations in the group costs were simulated (sensitivity analysis; see online supplementary eTable 1) and the cost-effectiveness relationship per patient was performed (see online supplementary eTable 2). The cost differences were mainly related to clinical monitoring in the SU. Based on the quality-adjusted life year (QUALY) analysis, the effectiveness was similar for the PC and SU protocols $(0.009 \pm 0.033$ for PC and $0.017 \pm 0.042$ for $\mathrm{SU} ; \mathrm{p}=0.13$ ). Therefore, the resulting incremental cost-effectiveness ratio represents a slight but not significant decrease in effectiveness, with an estimated savings of $€ 26$ 852 per QUALY for the PC setting compared with the SU setting (see online supplementary eFigure 1). The sensitivity analysis confirmed these findings. See the online supplement for additional information about the within-trial costs).

\section{DISCUSSION}

This study evaluated whether CPAP follow-up in a PC setting is as effective as the recommended conventional management in an SU setting in a sample of patients with OSA who were beginning CPAP treatment. The main finding was that the PC model was not inferior to the standard SU model in terms of our primary outcome measure, CPAP compliance. This main outcome was chosen as the objective measure to compare the effectiveness of these two settings. In addition, this study primarily indicated that the PC setting was a cost-effective alternative to follow-up in an SU.

For the secondary outcomes, the patients who were followed up in the SU setting reported a greater decrease in the ESS score and a higher degree of satisfaction with the medical treatment they obtained. However, the quality of life (EQ-5D) did not differ between the groups. We also found a slight increase in BMI in the PC group and a tendency toward better control of SBP and DBP.

These results extend previous studies that evaluated ambulatory models of sleep apnoea care. Mulgrew et $a l^{13}$ performed a

Table 3 Within-trial treatment and follow-up costs in the European context (average cost per randomised patient)

\begin{tabular}{|c|c|c|c|c|}
\hline & $\begin{array}{l}\text { Primary } \\
\text { care } \\
(n=101)(€)\end{array}$ & $\begin{array}{l}\text { Sleep } \\
\text { unit } \\
(n=109) \\
(€)\end{array}$ & $\begin{array}{l}\text { Difference } \\
(€)\end{array}$ & $\begin{array}{l}\text { ICER } \\
\text { (QUALYs) }\end{array}$ \\
\hline Training cost & 12.67 & 0 & 12.67 & \\
\hline Physician/nurse visits & 73.81 & 279.82 & -206.01 & \\
\hline $\begin{array}{l}\text { Telephone } \\
\text { consultations }\end{array}$ & 1.21 & 2.26 & -1.04 & \\
\hline CPAP treatment & 54.94 & 60.45 & -5.51 & \\
\hline Patient travel costs & 1.72 & 13.98 & -12.26 & \\
\hline Total cost per patient & 144.37 & 356.50 & -212.13 & 25434.91 \\
\hline
\end{tabular}


study in patients with high pre-test probabilities of moderate to severe OSA. The authors evaluated the utility of a simplified method that included portable monitoring and auto-titrating CPAP in the initial management of OSA and found no differences in the ESS score changes or the quality of life compared with specialist unit based care. Similarly, Kuna et $a l^{15}$ showed that functional outcomes related to the sleep questionnaire score and CPAP compliance of patients who were evaluated using an ambulatory strategy were not clinically inferior to those of patients who received laboratory-based care.

Other studies have evaluated the management of patients with suspected OSA in two different settings: PC and a specialist unit. Antic et $a l^{16}$ demonstrated that a simplified nurse-led model of care produced non-inferior results, including changes in the ESS scores and CPAP compliance, compared with physician-directed care in managing symptomatic moderatesevere OSA. More recently, Chai-Coetzer et $a l^{31}$ performed a randomised controlled trial of patients who presented for a PC consultation for any reason and were screened for moderate to severe OSA using a validated two-step method. ${ }^{32}$ The authors compared the clinical efficacy (changes in the ESS score) of a simplified model of diagnosis and care in PC relative to that a similar model at a specialist sleep centre. They found that after 6 months of follow-up, the patients with OSA who were treated under the PC model compared with a specialist model did not exhibit worse sleepiness scores. The authors concluded that the two care models may be comparable. Similarly to Chai-Coetzer et al, we found that the CPAP compliance of the patients who were followed up in a PC setting was similar to that of the patients who were followed up in a SU setting. Conversely, however, the patients who were followed up at the SU reported a larger decrease in ESS scores than those who were followed up in the PC units. Additionally, the SU group reported increased satisfaction with the medical treatment obtained. It is important to consider that both the ESS tests and satisfaction scales are subjective measures that might reflect an increased sense of self-reported well-being among the patients who were treated in a specialised setting.

There are several notable differences between the study of Chai-Coetzer et al and our study. Whereas the study of Chai-Coetzer et al included patients who presented for a PC consultation for any reason and who had a high diagnostic likelihood of OSA, we included patients who were diagnosed with OSA in an SU and required CPAP treatment. Additionally, the study of Chai-Coetzer et al evaluated the entire diagnostic process, from the patient's diagnostic features to the treatment decision and clinical follow-up. However, in our study, we analysed the role of the PC in the follow-up of patients with OSA who were receiving CPAP treatment.

Interestingly and for unknown reasons, in this study we found that in the PC group, the BMI was slightly but significantly increased. In addition, there was a tendency towards decreased blood pressure (during the follow-up, no significant between-group differences in the antihypertensive treatment were seen).

Additionally, we examined the within-study costs. We found that PC monitoring resulted in a cost savings of $60 \%$ compared with SU monitoring. Similar to our findings, the Chai-Coetzer et al study ${ }^{31}$ reported that the PC follow-up costs were $61.4 \%$ lower than the SU follow-up costs. Interestingly, the cost savings were similar in two different geographical clinical settings (Australia and Spain). Other studies also reported a cost reduction in the PC management of sleep apnoea. Antic et al ${ }^{16}$ demonstrated that for patients assigned to a nurse-led approach, a within-study cost saving of \$A1111 per patient was achieved.
These results suggest that follow-up provided in a PC setting is a cost-effective alternative to conventional SU follow-up. Additionally, it is important to consider that the cost calculation in our study assumed the cost of the PC training programme and imputed only for the patients who were included in this study and were followed up in the PC setting. In a real situation in which PC personnel provided follow-up for patients with OSA, the training programme would be profitable for a larger number of patients. This indicates that the cost of follow-up in PC would be even lower than the cost calculated in this study.

The strengths of our study include its design, which is closely associated with clinical practice; therefore, the findings are easily generalisable. The findings of this study indicate that PC can be incorporated into the clinical management of patients with sleep apnoea in a manner similar to that used for other chronic diseases, thereby achieving results equivalent to those obtained in specialised SUs but with a lower cost. Finally, equivalence between the two settings is demonstrated by a high level of CPAP compliance (about $5 \mathrm{~h}$ per night).

This study has one limitation. It was performed in a region of Catalonia in Spain; therefore, cost differences between the two settings may be different from those in other countries. Nevertheless, previous studies performed in other countries have shown cost savings similar to those shown in our study, ${ }^{31}$ and our sensitivity analysis confirmed these results.

In conclusion, the findings of this randomised controlled trial show that among patients with OSA, treatment under a PC model compared with a specialist model did not result in worse CPAP compliance. Therefore, follow-up in PC settings is a realistic and cost-effective alternative to conventional SU follow-up.

Collaborators Respiratory Medicine Research Group (collaborating group)—Eugeni Paredes, Núria Roquet, Mercè Lavega, Josep Sangrá, Núria Tribó, Belen Malla, Eugenia Obis, Carme Juni, Marisa Regany, Olga Minguez, Lydia Pasual, Silvia Gómez, Anabel Castro, Nuria Tarraubella, Cecilia Turino, Miguel A Negrín.

Contributors Study design: MS, NN, JD-C and FB; data acquisition: NN, AC, SS, $M G, F F, I L, M L, M C U, T A, A F$ and FA; data analysis and interpretation: MS, NN, JFM, JV, F-JV-P and FB; manuscript draft and revision for intellectual content and approval of the final version: MS, NN, AC, JFM, JD-C, JV, SS, AS, MG, FF, IL, ML, $M C U, T A, A F, F A, F-J V-P$ and FB. Guarantor of the study: FB.

Funding This study was supported by the Instituto de Salud Carlos III (PI12/01499) (Fondo de Investigaciones Sanitarias, Ministerio de Sanidad y Consumo, Spain), ECO2013-47092 (Ministerio de Economía y Competitividad, Spain), Spanish Respiratory Society (SEPAR), Menarini, Barcelona (Spain) and Associació Lleidatana de Respiratori (ALLER).

Competing interests None.

Patient consent Obtained.

Ethics approval Arnau University Hospital CEIC (CEIC-884).

Provenance and peer review Not commissioned; externally peer reviewed.

\section{REFERENCES}

1 Young T, Palta M, Dempsey J, et al. The occurrence of sleep-disordered breathing among middle-aged adults. N Engl J Med 1993;328:1230-5.

2 Peppard PE, Young T, Barnet JH, et al. Increased prevalence of sleep-disordered breathing in adults. Am J Epidemiol 2013;177:1006-14.

3 Duran J, Esnaola S, Rubio R, et al. Obstructive sleep apnea-hypopnea and related clinical features in a population-based sample of subjects aged 30 to $70 \mathrm{yr}$. Am J Respir Crit Care Med 2001;163:685-9.

4 D'Ambrosio C, Bowman T, Mohsenin V. Quality of life in patients with obstructive sleep apnea: effect of nasal continuous positive airway pressure-a prospective study. Chest 1999;115:123-9.

5 Nieto FJ, Young TB, Lind BK, et al. Association of sleep-disordered breathing, sleep apnea and hypertension in a large community-based study. Sleep Heart Health Study. JAMA 2000;283:1829-36.

6 Barbé F, Durán-Cantolla J, Capote F, et al. Long-term effect of continuous positive airway pressure in hypertensive patients with sleep apnea. Am J Respir Crit Care Med 2010;181:718-26. 
7 Pack Al, Gislason T. Obstructive sleep apnea and cardiovascular disease: a perspective and future directions. Prog Cardiovasc Dis 2009;51:434-51.

8 Parra 0, Arboix A, Bechich S, et al. Time course of sleep-related breathing disorders in first-ever stroke or transient ischemic attack. Am J Respir Crit Care Med 2000;161:375-80.

9 Terán-Santos J, Jiménez-Gómez A, Cordero-Guevara J. The association between sleep apnea and the risk of traffic accidents. Cooperative Group Burgos-Santander. N Engl J Med 1999;340:847-51.

10 Rodenstein D. Sleep apnea: traffic and occupational accidents--individual risks, socioeconomic and legal implications. Respiration 2009;78:241-8.

11 Marin JM, Carrizo SJ, Vicente E, et al. Long-term cardiovascular outcomes in men with obstructive sleep apnoea-hypopnoea with or without treatment with continuous positive airway pressure: an observational study. Lancet 2005;365:1046-53.

12 Andreu AL, Chiner E, Sancho-Chust JN, et al. Effect of an ambulatory diagnostic and treatment programme in patients with sleep apnoea. Eur Respir $J$ 2012;39:305-12.

13 Mulgrew AT, Fox N, Ayas NT, et al. Diagnosis and initial management of obstructive sleep apnea without polysomnography: a randomized validation study. Ann Intern Med 2007;146:157-66

14 Berry RB, Hill G, Thompson L, et al. Portable monitoring and autotitration versus polysomnography for the diagnosis and treatment of sleep apnea. Sleep 2008;31:1423-31.

15 Kuna ST, Gurubhagavatula I, Maislin G, et al. Noninferiority of functional outcome in ambulatory management of obstructive sleep apnea. Am J Respir Crit Care Med 2011;183:1238-44.

16 Antic NA, Buchan C, Esterman A, et al. A randomized controlled trial of nurse-led care for symptomatic moderate-severe obstructive sleep apnea. Am J Respir Crit Care Med 2009;179:501-8.

17 Brusamento S, Legido-Quigley H, Panteli D, et al. Assessing the effectiveness of strategies to implement clinical guidelines for the management of chronic diseases at primary care level in EU member states: a systematic review. Health Policy 2012;107:168-83.

18 Ballester $E$, Badia JR, Hernandez $L$, et al. Evidence of the effectiveness of continuous positive airway pressure in the treatment of sleep apnea/hypopnea syndrome. Am J Respir Crit Care Med 1999;159:495-501.
19 Engleman HM, Kingshott RN, Wraith PK, et al. Randomized placebo-controlled crossover trial of continuous positive airway pressure for mild sleep apnea/hypopnea syndrome. Am J Respir Crit Care Med 1999;159:461-7.

20 McArdle N, Devereux G, Heidarnejad H, et al. Long-term use of CPAP therapy for sleep apnea/hypopnea syndrome. Am J Respir Crit Care Med 1999;159:1108-14.

21 Weaver TE, Grunstein RR. Adherence to continuous positive airway pressure therapy: the challenge to effective treatment. Proc Am Thorac Soc 2008;5:173-8.

22 Martínez-García MA, Soler-Cataluña JJ, Román-Sánchez P, et al. Efficacy of a training program on sleep apnea-hypopnea syndrome aimed at primary care physicians. Arch Bronconeumol 2008;44:15-21.

23 Fletcher EC, Luckett RA. The effect of positive reinforcement on hourly compliance in nasal continuous positive airway pressure users with obstructive sleep apnea. Am Rev Respir Dis 1991;143:936-41.

24 Lloberes P, Durán-Cantolla J, Martínez-García MA, et al. Diagnosis and treatment of sleep apnea-hypopnea syndrome. Spanish Society of Pulmonology and Thoracic Surgery. Arch Bronconeumol 2011;47:143-56.

25 Ruehland WR, Rochford PD, O'Donoghue FJ, et al. The new AASM criteria for scoring hypopneas: impact on the apnea hypopnea index. Sleep 2009;32:150-7.

26 Masa JF, Jiménez A, Durán J, et al. Alternative methods of titrating continuous positive airway pressure: a large multicenter study. Am J Respir Crit Care Med 2004;170:1218-24.

27 Chiner E, Arriero JM, Signes-Costa J, et al. Validation of the Spanish version of the Epworth Sleepiness Scale in patients with a sleep apnea syndrome. Arch Bronconeumol 1999;35:422-7.

28 Chobanian AV, Bakris GL, Black HR, et al. The Seventh Report of the Joint National Committee on Prevention, Detection, Evaluation and Treatment of High Blood Pressure: the JNC 7 report. JAMA 2003;289:2560-72.

29 Su Y-S, Gelman A, Hill J, et al. Multiple imputation with diagnostics (mi) in R: opening windows into the black box. J Stat Softw 2011;45.

30 Rubin DB. Multiple imputation for nonresponse in surveys. John Wiley \& Sons, Inc., 1987.

31 Chai-Coetzer CL, Antic NA, Rowland LS, et al. Primary care vs specialist sleep center management of obstructive sleep apnea and daytime sleepiness and quality of life: a randomized trial. JAMA 2013;309:997-1004.

32 Chai-Coetzer CL, Antic NA, Rowland LS, et al. A simplified model of screening questionnaire and home monitoring for obstructive sleep apnoea in primary care. Thorax 2011;66:213-19. 